\title{
New solutions for horse shelters to connect to the equestrian paths
}

\author{
Gianluca Bambi, Massimo Monti, Matteo Barbari \\ Dipartimento di Gestione dei Sistemi Agrari, Alimentari e Forestali, GESAAF, Firenze, Italy
}

\begin{abstract}
A rational and modern network of riding trails involves the building of specific structures for the horses according to the new needs of equestrian tourists. These shelters require appropriate technical models that today cannot be found easily in the Italian or foreign literature. Over the years this gap has led to the development of the practice "do it yourself", following old techniques of construction, not able to meet the new demands of the market of horse tourism. This research has highlighted two different solutions that can meet the needs of tourists riding today, in accordance with the laws about the construction and the health part. These structures have been designed observing the principles of low impact, low cost, easy installation, complete reuse. Two kinds of structures have been planned. Temporary stay horse shelter: building to put in resting places of interest along the path (historic villages, monasteries, etc.), where it is possible to arrange the horses for a few hours and allow to the riders to make a careful visit of places of interest. Overnight stay horse shelter: structure to put in particular points where horses and riders can spend the night. A new type of horse barn with annexed feed storage and saddle room. The structure is dynamic, due to the possibility to change quickly the position of the horses (max 8 places).
\end{abstract}

\section{Introduction}

In Italy a growing number of projects involves the creation or promotion of riding trails. These projects are often developed by public offices, such as regions, provinces and natural park authorities. Therefore the horse tourist sector has become part of the dynamics of territorial development.

The "equitourism" is one of best hiking ways to live landscape intimately and naturally, to arouse emotions in the rider that only the horse can transmit. Tuscany is a region that definitely offers an excep-

Correspondence: Matteo Barbari, Dipartimento di Gestione dei Sistemi Agrari, Alimentari e Forestali, GESAAF - via San Bonaventura 1350145 Firenze-Italy.

E-mail: matteo.barbari@unifi.it

Key words: horse shelter, horse paths, wood building

(C) Copyright G. Bambi et al., 2013

Licensee PAGEPress, Italy

Journal of Agricultural Engineering 2013; XLIV(s2):e35

doi:10.4081/jae.2013.s2.e35

This article is distributed under the terms of the Creative Commons Attribution Noncommercial License (by-nc 3.0) which permits any noncommercial use, distribution, and reproduction in any medium, provided the original author(s) and source are credited. tional opportunity for the development of equestrian tourism, thanks to the wealth of its natural and environmental heritage and to the craft traditions, history and culture of its inhabitants. Today the equestrian tourism is not any more a small market, but has become a true form to spend time to discover the landscape. It is like a return to tradition: the horse is no longer used only for sports, but to travel from one point to another, as has been for many centuries, like a true travel companion that can help to relate better with the nature.

In Europe there are already two important cases of successful integrated offering of equestrian tourism. The first system is represented by Ireland (already fully operational), the second is located in Italy and is represented by the Abruzzo Region. In particular, this project looks at the model of Ireland, which has been able to relate public and private initiatives by creating a tourism product that has turned the horse culture of the territory in a special tourist offer "all season" and to generate local economic value.

A rational and modern network of riding trails involves the building of specific structures for the horses according to the new needs of equestrian tourists. The Department of Tourism of Tuscany Region, in collaboration with the Fitetrec Tuscany (Italian Federation Equestrian Tourism), identified two years ago five rings of horse trails. The project "Riding Trails Tuscan" is part of the interregional cooperation actions for the development of Equestrian Tourism, following a strategic segment of a new tourist offer based on criteria of sustainable development.

\section{Materials and methods}

The research was developed thanks the interaction between the Department and the Tuscany Region, for the realization of a guidelines manual for the realization of riding trails. The research has started with an analysis of the accommodation requests made by the riders about the horse shelter. This survey was done in collaboration with the Italian Equestrian Federation. To facilitate the construction by private people and for a quick approval and inclusion in the local laws, the horse shelter have been designed following these principles: low impact, low cost, easy installation, complete reuse. One of the problems that emerged during the research was the opportunity or less of the realization of one building for the manure storage. The research, after a series of meetings with the local health office of the Tuscany Region, has shown some final considerations very helpful for the local authorities. The shelters are completely made in wood and include, when required, the use of reinforced concrete. The cladding is made in wood as well as the internal partitions among horses. The internal cladding, in one of the two types designed, is completely removable thanks to rails, hooks and iron chains.

\section{Results}

In this first phase, the research has identified two different propos- 
als of horse shelter, with solutions that can satisfy the needs of modern tourist riding and have correspondence with the legislation about constructive sanitation. These buildings, preferably made with materials and according to traditional types, must follow the criteria of correct insertion into the landscape and reducing environmental impact.

\section{Overnight stay horse shelter}

This type of horse shelter must be connected to an official accommodation for the riders (according to the regional law LR 42/2000). It is an innovative type of horse shelter, designed to meet the different needs. In fact, the structure can be used like a loose box or a single stall, with easy operations to change disposition requiring few minutes. In this way two possibilities of housing can be offered, taking into account that some horses do not tolerate conditional admission in stall. The building allows to accommodate up to 8 horses in stalls or 4 horses in loose boxes. The number can change in mixed solutions $(4+2,6+1,2+3)$.

Close to the area for horse shelter there is a room used to store feed and saddles and also used as emergency shelter for riders. The module is dimensioned so that the horses are placed head-to-head and have a width at minimum of $1.47 \mathrm{~m}$ and a length of $3.07 \mathrm{~m}$. The building must be equipped with artificial lighting, fixed or mobile in order to ensure the inspection operations during the night. Inside every stall a drinking trough and a manger are placed in the corners opposite the opening (Figures 1 and 2).

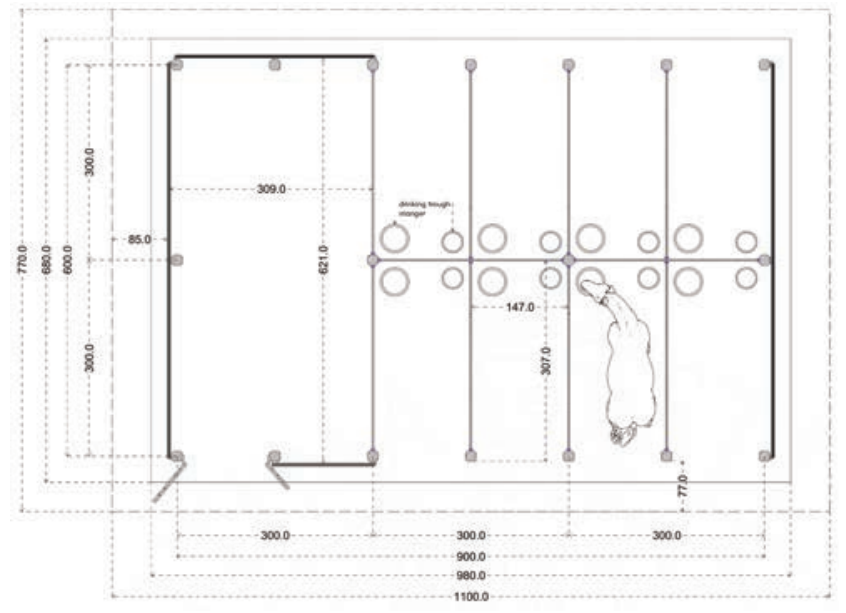

Figure 1. Layout of the overnight stay horse shelter.

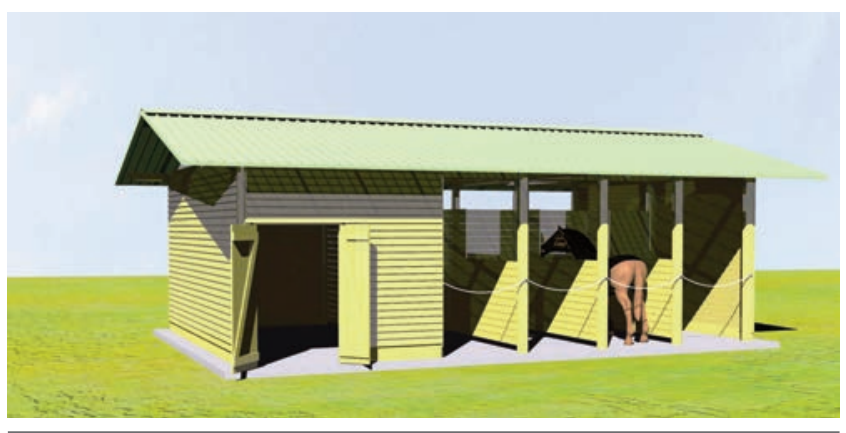

Figure 2. Perspective view of the overnight stay horse shelter.

\section{Temporary stay horse shelter}

This type of shelter is based on the concept of old horse post station, to put in resting places of interest along the path. The building is modular and does not have the room for storage of saddles and feed. It is advisable nevertheless to provide a fence to support the saddles. An external drinking trough has to be provided (Figures 3 and 4)

In both the structures the following elements must be present:

- iron ring to tie in correct way the horses, preferably with a rope fitted with a counterweight to avoid accidents;

- sink to wash the horse tack and a rubber tube (at minimum $4 \mathrm{~m}$ ) to clean the horses;

- chain needed in the bottom of the stall (behind the horse), designed to contain and give security to fearful or nervous horses.

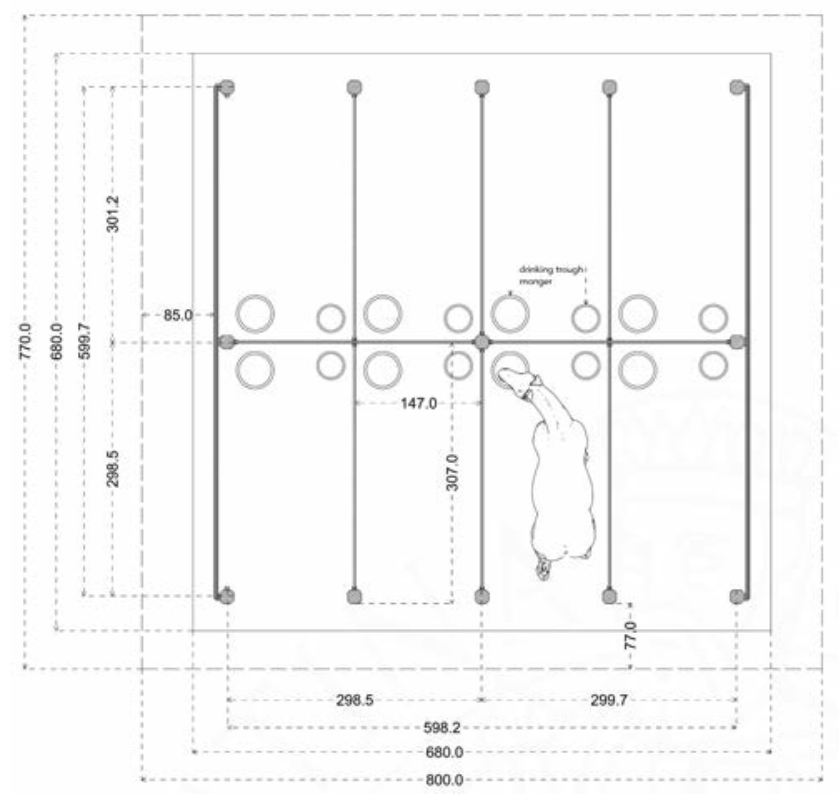

Figure 3. Layout of the temporary stay horse shelter.

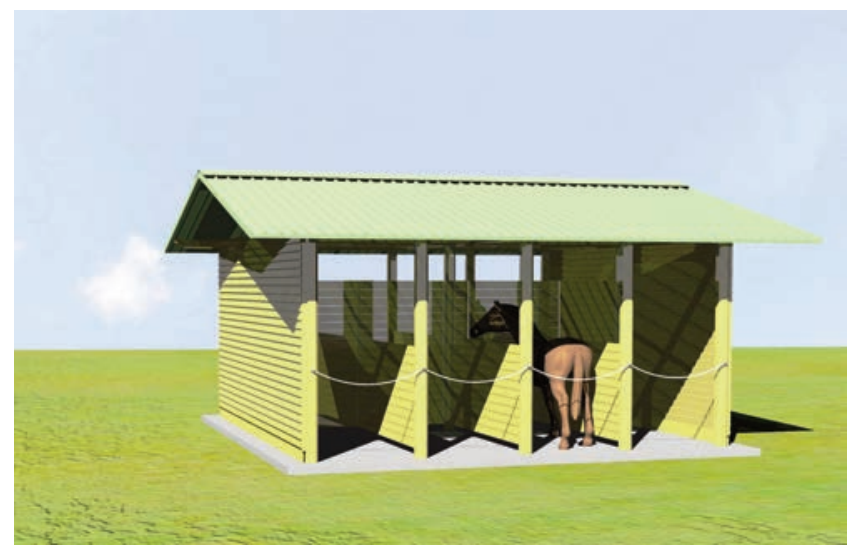

Figure 4. Perspective view of the temporary stay horse shelter. 


\section{Health and hygiene guidelines for the manure}

The health and hygiene standards to build these particular temporary horse shelters is quite complex because the local municipal regulations of hygiene are quite different in the Tuscany Region. Indeed, if it is true that this building constructed for the custody of horses in theory should follow the veterinary police regulations, it is also true that it is a temporary shelter, where the horses remain inside for few hours. This has led to different interpretations by the veterinary offices dislocated in the Region.

The legislation imposes a waterproof flooring for a complete disinfection and cleaning. However, taking into account that the shelter has to be suitable for temporary use, different design solutions could be provided. These include the creation of stalls with interlocking concrete tiles or the preparation of the simple bare ground with several layers of cobblestones. The proposed solutions are based on the use of reinforced concrete foundation, that is the most request.

Another consideration regards the possibility or not to build the place for the manure storage. One solution is represented by the possibility to put the manure in special sealed containers (such as garbage bin), to empty into an official place for the manure. Alternatively a plastic sheet on the ground could be used, with the disadvantage that it must be replaced each time the manure is removed.

The municipal regulations often require the presence of a reinforced concrete flooring, increasing the total cost of construction. Other national regulations to follow are those concerning the distances for positioning and for sizing. The storage period for the horse manure can be smaller than for others animals (up to 90 days). Usually a surface of $3 \mathrm{~m}^{2} /$ horse for a storage period of 180 days is planned, so $1.5 \mathrm{~m}^{2} /$ horse for 90 days. Considering a presence of horses of 2-3 days per week (35 days in the 3 months of storage), and occupation of the shelter mainly overnight (10-12 hours/day), a further reduction of 50\% can be considered. Therefore for a shelter with 8 horses a rectangular surface of about $3 \mathrm{~m}^{2}$ is required. The catch basin for the urines is not required because these are totally absorbed by the litter (straw, wood shavings or other).

\section{Conclusions}

The main aim of the research was to propose a series of projects for housing of horses to service riding nets. The structures were designed following the general principles of the Horse Code for the Protection and Management prepared by the Ministry of Labour, Health and Social Policies.

The proposed solutions can meet the needs of the modern tourist riding and have correspondence with the local and regional legislation.

The designed solutions have to be considered type-projects, to be built in the whole national territory, leaving the final structural calculations to specific individual cases.

\section{References}

Barbari, M., Conti, L., Monti, M., Pellegrini, P., Rossi, G., Simonini, S., Sorbetti Guerri, F. (2012). Antropizzazioni decostruibili per il nonconsumo del territorio rurale - Parte I: dallo sviluppo sostenibile alle antropizzazioni decostruibili. L'Edilizia Rurale tra Sviluppo Tecnologico e Tutela del Territorio. Firenze: AIIA - Associazione Italiana di Ingegneria Agraria.

Barbari, M., Conti, L., Monti, M., Pellegrini, P., Rossi, G., Simonini, S., Sorbetti Guerri, F. (2012). Antropizzazioni decostruibili per il nonconsumo del territorio rurale - Parte II: progettazione per la decostruibilità. L'Edilizia Rurale tra Sviluppo Tecnologico e Tutela del Territorio. FIRENZE: AIIA - Associazione Italiana di Ingegneria Agraria.

Barbari, M., Monti, M., Pellegrini, P., Sorbetti Guerri, F. (2003). La costruzione di edifici agricoli in legno massiccio sulla base di progetti tipo. In Costruire in legno - Progetti tipo di fabbricati ed annessi agricoli (2 ed.). Firenze, Italia: ARSIA Regione Toscana.

Giordano, G., Ceccotti, A., Uzielli, L. (1999). Tecnica delle costruzioni in legno (5th ed.). Milano, Italia: Hoepli.

Monti, M., Pellegrini, P. (2005). Impiego strutturale del legno massiccio negli edifici agricoli alla luce dell'evoluzione normativa. L'ingegneria agraria per lo sviluppo sostenibile dell'area mediterranea. Catania.

Schouten, J., Addis, W. (2004). Design for deconstruction. Principles of design to facilitate reuse and recycling. CIRIA. 